\section{Dr. Marchesoni and Dr. Atzeni reply}

\section{To the Editor:}

We thank Dr. Konno for his interest in our study ${ }^{1}$. Extraarticular pain in patients with psoriatic arthritis (PsA) may be due to enthesitis or fibromyalgia (FM). The aim of our study ${ }^{2}$ was to establish which of the clinical characteristics that can be easily recorded during a standard rheumatological evaluation might help to distinguish the 2 conditions, and the results indicated that the number of somatic symptoms and the number of tender points were independent predictors of FM.

The recently published preliminary FM diagnostic criteria ${ }^{3}$ suggest a new case definition that is based mainly on a widespread pain index and the severity of somatic symptoms, but does not include number of tender points. It is possible that the application of these new criteria will be enough to identify PsA patients with FM, although this will need to be demonstrated by appropriate studies. We used the old American College of Rheumatology (ACR) criteria ${ }^{4}$ because the new ones were not available at the time. However, as the results showed the importance of somatic symptoms, they are in line with the new criteria. Interestingly, one of the conditions required by the new criteria is that "the patient does not have a disorder that would otherwise explain the pain." As widespread pain due to polyenthesitis is one of these situations, it is clear that we need as many means as possible to make sure of the diagnosis, and the tender point count seems to be one of these.

It is likely that ultrasonography (US) of the entheses will become a powerful new means of revealing the presence of inflammation. However, there is an absolute need for precise definitions of the changes, standardized evaluation methods, and specific training in order to avoid a misdiagnosis. Dr. Konno found that US revealed erosive changes at entheseal sites not only in a very small proportion of patients with FM, as expected, but also in an utterly unexpected $47 \%$ of patients with RA, thus showing that, without appropriate standardization, entheseal US is likely to be more confusing than helpful.
Although psoriatic arthritis is one of the spondyloarthritides (SpA), we would suggest caution in extending the results of our study to the entire spectrum of SpA. FM may occur in patients with SpA and may be difficult to distinguish from polyenthesitis. The new FM diagnostic criteria might be useful because they consider only the patient's reported symptoms and do not include tender point counts. As many of these points overlap with entheseal sites, a diagnostic method that does not involve tender point counts should prevent erroneous diagnoses of FM in patients with SpA. However, because $\mathrm{SpA}$ as well as other osteoarticular conditions may be responsible for a painful syndrome indistinguishable for intensity and localization from FM, to determine whether a patient with SpA with widespread pain also has FM can be very difficult.

ANTONIO MARCHESONI, MD, Rheumatology Day Hospital, Istituto Ortopedico G. Pini, Milan; FABIOLA ATZENI, MD, Unità di

Reumatologia, Ospedale Sacco, Milan, Italy. Address correspondence to Dr. Marchesoni; E-mail: marchesoni@gpini.it

\section{REFERENCES}

1. Konno T. Differentiation of the clinical features of psoriatic arthritis and fibromyalgia [letter]. J Rheumatol 2012;39:XXXX.

2. Marchesoni A, Atzeni F, Spadaro A, Lubrano E, Provenzano G, Cauli A, et al. Identification of the clinical features distinguishing psoriatic arthritis and fibromyalgia. J Rheumatol 2012;39:849-55.

3. Wolfe F, Clauw DJ, Fitzcharles MA, Goldenberg DL, Katz RS, Mease P, et al. The American College of Rheumatology preliminary diagnostic criteria for fibromyalgia and measurement of symptom severity. Arthritis Care Res 2010;62:600-10.

4. Wolfe F, Smythe HA, Yunus MB, Bennett RM, Bombardier C, Goldenberg DL, et al. The American College of Rheumatology 1990 criteria for the classification of fibromyalgia. Report of the Multicenter Criteria Committee. Arthritis Rheum 1990;33:160-72.

J Rheumatol 2012;39:11; doi:10.3899/jrheum.120875 